\title{
FATORES ASSOCIADOS AO FRACO ACESSO DAS MENINAS AO ENSINO PRIMÁRIO EM MOÇAMBIQUE
}

\author{
Octávio José Zimbico* \\ lattes.cnpq.br/7897136419385616
}

\begin{abstract}
Resumo: $\mathrm{O}$ fraco acesso das meninas à escola primária em Moçambique está no centro da questão deste texto, que tem como problema o fato de não se saber as razões por que, historicamente, as meninas têm estado em desvantagem numérica, na escola primária, comparativamente com os meninos. O objetivo é identificar e tipificar as possíveis fatores associados a este fenômeno desde o período anterior a 1975, ano em que o país alcançou a sua independência do domínio colonial português. Do ponto de vista metodológico, a revisão bibliográfica, o estudo da legislação, a análise dos dados estatísticos (primários e secundários) constituem a base de sustentação das ideias deste trabalho, de natureza histórica. A análise desse material revela que, por um lado, fatores socioculturais conjugados com os de natureza política têm estado na origem do fraco acesso das meninas à escola primária em Moçambique, desde a segunda metade do século XIX. Por outro, esses fatores e o modo de organização e funcionamento da sociedade moçambicana influenciam-se mutuamente.
\end{abstract}

Palavras-chave: Gênero; Meninas; Acesso ao Ensino Primário; História da Educação em Moçambique.

\section{FACTORS ASSOCIATED WITH GIRLS' POOR ACCESS TO PRIMARY EDUCATION IN MOZAMBIQUE}

\begin{abstract}
The poor access of girls to Primary Education in Mozambique is at the heart of this text, which has as the problem of not knowing the reasons why, historically, girls have been numerically disadvantaged in Primary Education, when compared to Boys. The aim is to identify and typify the possible factors associated with this phenomenon, from the period prior to 1975 , the year in which the country reached its independence from Portuguese colonial rule. From the methodological point of view, the bibliographic review, the study of legislation, and the analysis of statistical data (primary and second-
\end{abstract}

* Doutor em Educação pela Universidade do Estado do Rio de Janeiro (Brasil). Contato: o.zimbico@gmail.com. 
ary) are the basis for sustaining the ideas of this historical work. The analysis of this material reveals that, on the one hand, social and cultural factors linked with those of a political nature have been the origin of the poor access of girls to primary school in Mozambique, since the second half of the nineteenth century. On the other hand, these factors and the way of organization and functioning of Mozambican society influence each other.

Keywords: Gender; Girls; Access to Primary Education; History of Education in Mozambique.

$$
\text { * } \quad * \quad *
$$

\section{Introdução}

Afrontámos a herança do analfabetismo generalizado, da doença, da miséria e da fome. Encontrámos o nosso povo, e em particular o povo do campo, vivendo em condições sub-humanas de miséria e de exploração. Encontrámos destruição, ressentimento e ódio criados por séculos de opressão, estimulados pela guerra colonial de agressão que os reacionários, colonialistas e fascistas, desencadearam com o fim de semear a divisão e confusão.

Samora Moisés Machel (1978)

Desde 1975 que a Constituição de Moçambique, apesar de sucessivas revisões ${ }^{1}$, determina igualdade e equidade de direitos e oportunidades entre homens e mulheres, em todas as áreas de interesse, incluindo na educação (cf. o art. 31 da Constituição de 1975). Aliás, desde a luta armada de liberta-

1 A constituição de Moçambique sofreu alterações pontuais em 1976, 1977, 1978, 1982, 1984 e 1986. A de 1990, resulta de uma revisão que trouxe mudanças em vários campos da vida do país, que já começavam a manifestar-se, principalmente na área econômica, a partir de 1984. A constituição de 1990 sofreu três alterações pontuais: duas em 1992 e uma em 1996. A última revisão é de 2004 que visa aprimorar os interesses do país no poder legislativo. 


\section{Revista de História e}

Historiografia da Educação

ção nacional (1964-1974) que a Frente de Libertação de Moçambique (FRELIMO) vinha "emancipando a mulher", defendendo que ela e o homem tivessem igualdade e equidade de direitos e oportunidades. Moçambique subscreveu a declaração mundial de Educação Para Todos (EPT) em Jomtien, na Tailândia, de 5 a 9 de março de 1990, comprometendo-se a satisfazer as necessidades básicas de aprendizagem através da garantia da escolarização primária para todos até 2000. Estimava-se que em 1990 cerca de 100 milhões de crianças no mundo, das quais 60 milhões eram meninas, não tinham acesso à escola primária; tal como, também, 960 milhões de adultos, dois terços dos quais mulheres, eram analfabetos (DELORS, 1996). No caso de Moçambique, em 1992, Aniceto dos Muchangos, antigo Ministro da Educação, considerava que dadas as condições do país, importava que se tivesse consciência do que era necessário fazer com relação às crianças, sobretudo, como também relativamente aos adultos que não tinham tido acesso à instrução. Segundo dos Muchangos, seria uma utopia a ideia de EPT até 2000, ou seja, dentro de oito anos, para um país cuja taxa de analfabetismo era das mais altas do mundo e acima dos $70 \%{ }^{2}$.

Dez anos mais tarde (em Dacar, Senegal, de 26 a 28 de abril de 2000), os participantes da Cúpula Mundial de Educação para Todos, comprometeram-se a alcançar seis metas de EPT para cada cidadão e cada sociedade. Na ocasião, consideraram "inaceitável" que em 2000, no mundo, mais de 113 milhões de crianças continuassem sem acesso ao ensino primário; que 880 milhões de adultos fossem analfabetos; e que a discriminação de gênero continuasse a caracterizar os sistemas educativos. Segundo este compromisso coletivo, até 2015 todas as crianças deviam ter uma escolarização básica gratuita e eliminadas as disparidades de gênero no ensino primário, com enfoque na garantia ao acesso equitativo das meninas a uma educação básica de qualidade3. Para isso, cabia aos governos assegurar que

2 Trecho retirado do texto "Educação: tempo de adequação da linguagem", publicado na Revista Tempo, n. ${ }^{0}$ 1146, p. 18, de 08/11/1992.

3 Compromisso Coletivo n. ${ }^{\circ} 7$ do Marco de Ação de Dacar (UNESCO, 2001, p. 7). 


\section{Revista de Hlistória e}

Historiografia da Educação

os objetivos e as metas de EPT fossem alcançados e mantidos. No entanto, durante a recolha de dados para a tese de doutorado em Educação, entre 2015 e 2016, constatámos que apesar dos avanços alcançados, a escolarização primária para todos em Moçambique ainda estava longe de ser alcançada. Outrossim, analisadas na ótica de gênero, as estatísticas revelam que mais meninos têm tido acesso à escola primária do que meninas, apesar da superioridade numérica da população escolarizável de meninas.

Neste contexto, constitui objetivo deste texto, identificar e tipificar os possíveis fatores associados ao fenômeno do fraco acesso das meninas à escola primária, com base numa pesquisa de natureza histórica, partindo de um breve olhar à situação atual da escolarização primária das meninas para procurar estabelecer uma provável ligação histórica entre o ensino primário colonial das meninas (desde a segunda metade do século XIX) até à atualidade. Na busca de respostas ao problema formulado neste trabalho, colocamos as seguintes perguntas: como era o acesso das meninas à escola primária, do ponto de vista quantitativo, desde a segunda metade do século XIX até ao terceiro quartel do século XX? Quais os prováveis fatores associados a essa tendência dos efetivos escolares? Como podem ser tipificados e classificados esses fatores?

A escolha da segunda metade do século XIX justifica-se por ter sido um momento em que começaram a vigorar as primeiras iniciativas legislativas de instrução pública na antiga colônia portuguesa de Moçambique, enquanto o final do terceiro quartel do século XX é marcado pela independência de Moçambique (em 25 de junho de 1975). A partir deste momento os moçambicanos inciaram um projeto de uma nova escola primária, impulsionada pela "revolução socialista moçambicana" e baseada nos princípios de igualdade e equidade, independentemente do sexo, cor, origem geográfica, estatuto social, religião, entre outros atributos, diferentemente do que vinha acontecendo no período anterior a 1975 .

Em termos metodológicos, esta pesquisa é de carácter histórico e emprega diferentes dados, na busca de respostas às perguntas de 
investigação. O objetivo é suplementar a informação, permitindo a triangulação dos dados, mediante o uso de diversas fontes na abordagem do problema de pesquisa, sob diferentes visões. Outras intenções são: maximizar as potencialidades das abordagens qualitativas e quantitativas; minimizar as fraquezas advindas das limitações de cada abordagem; e usar a pluralidade de pontos de vista sobre a oferta do EP em Moçambique para enriquecer a reflexão. As pesquisas históricas têm o mérito de ajudar a avaliar os erros e êxitos do passado, para a partir dessas experiências melhorar-se o presente e projetar-se o futuro desejado. Nesta ordem de ideias, constituem fontes de pesquisa a bibliografia, a legislação, estatísticas de educação, recolhidos em acervos localizados na cidade de Maputo, entre 2015 e 2016. A legislação constitui material de trabalho para pesquisadores e responsáveis pela política educativa porque oferece uma visão de ideias e valores do passado, presente, e projetados para o futuro, identificando conflitos, consensos, continuidades, rupturas na definição e implementação da política educativa. Por sua vez, as estatísticas de educação fornecem elementos passíveis de análise histórica, podendo ser instrumento metodológico, para classificar, quantificar, cifrar realidades.

\section{Gênero e equidade de oportunidades: breve discussão}

Ser um membro masculino ou feminino numa sociedade tem certas características qualitativas que são atribuídas pela comunidade social e cultural ao indivíduo. Estas características constituem o gênero. Gênero pode ser definido como sendo o carácter qualitativo e interdependente de posições atribuídas às mulheres e aos homens em uma determinada sociedade (NAFUKO; AMUTABI; OTUNGA, 2005).

Do ponto de vista legal, o acesso à escola é um direito de todas as crianças, independentemente do sexo. No entanto, até meados da década 


\section{Revista de História e}

Historiografia da Educação

1990, a situação de recuperação econômica de Moçambique somente permitia que poucos meninos e meninas frequentassem a escola. $\mathrm{O}$ movimento a favor do tratamento especial dos direitos da mulher emergiu nos anos 1980, em resposta à "invisibilidade da prática de direitos humanos na esfera privada e um entendimento da responsabilidade do modelo patriarcal da organização social para a alienação dos direitos da mulher" (ANDRADE; OSÓRIO; TRINDADE, 2001, p. 26). Com efeito, o debate se desenvolvia em dois polos: um que argumentava que os direitos humanos cobrem invariavelmente ambos (homem e mulher), e outro que argumentava a favor da autonomia dos direitos da mulher.

Dos problemas com que muitas nações se debatem podemos destacar o "analfabetismo, doenças, pobreza e militarismo" (NAFUKO; AMUTABI; OTUNGA, 2005, p.284). Destes, o analfabetismo parece dos mais críticos. Tendo em conta que a educação pode ajudar a prevenir e eliminar disparidades de gênero e problemas sociais relacionados com o gênero, tais como a violência contra a mulher e abuso sexual de crianças por adultos, a escolarização das pessoas é vista como fator fundamental na definição das relações do poder de decisão na família. Na sociedade moçambicana existem reservas naturais dos homens para viver com mulheres instruídas, pois a instrução é considerada passível de debilitar o poder do homem. As estatísticas de educação revelam que do número total de analfabetos no mundo a maioria são mulheres, nalguns países acima de dois terços de analfabetos adultos. Devido à insuficiência de recursos, a educação torna-se muito onerosa. Assim, muitos países encontram-se num ciclo vicioso de pobreza, sendo sua prioridade satisfazer necessidades básicas (alimentação e vestuário), ao invés da educação. Em Moçambique, segundo o Instituto Nacional de Estatística, até 2009, cerca de 81\% de crianças em idade escolar frequentavam o ensino primário, das quais $80 \%$ de meninas. Mas nem todas as crianças que frequentam um certo nível de ensino conseguem concluí-lo, o que torna o cenário mais grave ainda. 


\section{Revista de História e}

Historiografia da Educação

De um modo geral, nas zonas urbanas, devido a intervenção frequentemente violenta da modernidade, a mulher e as famílias dirigidas por mulheres vêm aumentando sua intervenção. Visto que a teoria de investimento em capital humano atribui à educação o desencadeamento de mudanças e a eliminação de desigualdades sociais cuja origem não só está na escola, acredita-se que devidamente instruída, a mulher tenha mais condições para se libertar do controle masculino e exercer plenamente suas funções sociais. No entanto, devido a elementos de socialização que constroem a identidade dos seus membros, a partir da idade e do gênero, definindo-lhes os papéis sociais e determinando-lhes o destino, a família dirigida por mulheres é vista, tanto por homens tanto por mulheres, como incompleta.

A constituição de agregados chefiados por mulheres é, muitas vezes, uma manifestação de exclusão, e como antídoto, a intervenção na educação da família se deve desenvolver a dois níveis: primeiro, o conhecimento da lei e dos direitos da mulher nela consignados, e segundo, a alteração da mentalidade e conduta. Portanto, é neste segundo nível de intervenção que se torna fundamental a educação formal (na escola). Assim, a escola é, depois da família, "o agente de socialização responsável pela construção das identidades, ou seja, responsável pela legitimação ou não de elementos de socialização elaborados e transmitidos na família" (ANDRADE et al., 1998, p.140). Em zonas rurais de Moçambique, face a impossibilidade de todas as crianças frequentarem a escola, as famílias orientam a sua escolha em função do sexo, priorizando os meninos, porque deles se espera que chefiem famílias fortes econômica e culturalmente. Segundo o Ministério da Educação (MINED, 2003, p. 12),

Os pais privilegiam a escolaridade dos meninos, e mais ainda: a divisão social do trabalho, na base do gênero atribui às meninas, desde muito cedo, tarefas tradicionalmente consideradas da responsabilidade da mulher, o que dificulta o seu acesso à escola. 
A divisão do trabalho na família é considerada prejudicial a mulher por trabalhar mais horas em tarefas fundamentalmente não remuneradas. Essas assimetrias podem significar que as mulheres têm menos controle sobre os bens da família, ao mesmo tempo que mais responsabilidades. Segundo Van Klaveren et al. (2009, p.19), de 2002 a 2003, de toda a população economicamente ativa, "a média percentual da participação da mulher em diversas atividades econômicas em Moçambique foi de $62 \%$ na agricultura, $41 \%$ no comércio, 35\% nos serviços; sendo que os homens dominaram a função pública (65\%)".

De um modo geral, a participação dos homens em trabalhos domésticos embora se verifique, continua inferior à das mulheres. Esta situação impõe mais esforços com vista o incremento da participação dos homens nos trabalhos domésticos, o que constitui uma forma de inserção social desta camada.

\section{Equidade de gênero no acesso ao ensino primário no período colonial}

Em 1853, no centro administrativo da Ilha do Ibo, atual província de Cabo Delgado, região norte de Moçambique, uma escola com 30 meninos foi encerrada devido à precária qualidade dos professores que os assistiam, enquanto no mesmo ano, na mesma escola, a turma das meninas contava com apenas 8. À semelhança disso, em Quissanga, na mesma província, os alunos são referidos como tendo sido mal assistidos, em língua árabe, o que fez com que muitos residentes locais optassem por mandar seus educandos às escolas islâmicas da Ilha de Zanzibar4 (SHELDON, 1998, p.3). O decreto de 1845 só começou a produzir efeitos em 1849, quando em 30 de outubro desse ano, o Governador-geral Domingos Fortunato do Vale enviou ao

4 Administrativamente a Ilha de Zanzibar faz parte da atual República Unida da Tanzânia, região oriental de África, junto ao Oceano Índico. 
Ministro dos Negócios da Marinha e Ultramar uma ata da sessão em que o Conselho do Governo da Província de Moçambique apresentava um conjunto de propostas relativamente ao número de escolas de instrução pública que convinha haver na colônia, os locais onde deveriam ficar situadas, bem como a relação dos indivíduos que reuniam as condições necessárias para a constituição do Conselho de Instrução Pública (MADEIRA, 2007, p.338).

A tabela 1 mostra a designação e a localização das escolas que haviam sido propostas pelo Governador-geral de Moçambique:

Tabela 1 - Proposta de instalação de Escolas Públicas pelo Governador-geral em 1849. Fonte: MADEIRA (2007, p. 338).

\begin{tabular}{|c|c|c|c|}
\hline \multirow{2}{*}{ Designação da Escola } & \multirow{2}{*}{ Localização } & \multicolumn{2}{|c|}{ Sexo } \\
\hline & & Masculino & Feminino \\
\hline Escola de Instrução Pública do Ibo & Capital das Ilhas de Cabo Delgado & $\mathrm{X}$ & \\
\hline Escola da Cidade de Moçambique & Cidade de Moçambique & & $\mathrm{X}$ \\
\hline Escola Principal de Moçambique & Distrito de Moçambique & $\mathrm{X}$ & \\
\hline Escola da Vila de São Martinho & Distrito de Quelimane & $\mathrm{X}$ & \\
\hline Escola da Vila de Sena & Distrito de Quelimane & $\mathrm{X}$ & \\
\hline Escola da Vila de Tete & Distrito de Quelimane & $\mathrm{X}$ & \\
\hline Escola da Vila de Sofala & Distrito de Quelimane & $\mathrm{X}$ & \\
\hline Escola da Vila de Quelimane & Distrito de Quelimane & & $\mathrm{X}$ \\
\hline Escola da Vila de Inhambane & Distrito de Sofala & $\mathrm{X}$ & $\mathrm{X}$ \\
\hline Escola de Lourenço Marques & Distrito de Lourenço Marques & $\mathrm{X}$ & $\mathrm{X}$ \\
\hline
\end{tabular}

Na tabela 1 podemos observar que das 10 escolas propostas, apenas duas eram mistas, ou seja, simultaneamente para meninos e meninas e duas somente para meninas. As restantes seis eram exclusivamente destinadas a 


\section{Revista de Hlistória e}

Historiografia da Educação

meninos, o que denota o carácter discriminatório da rede escolar ora instalada, em função do papel que social atribuído à mulher5.

Uma Portaria de 14 de agosto de 1852 nomeara uma mestra de meninas de $2 .^{a}$ classe para a aula de instrução primária da Cidade de Moçambique, região Norte, nomeação essa confirmada pelo Decreto de 04 de maio de 1853, mandando executar aquela determinação. No entanto, em 1855, o Governador-geral Guedes de Carvalho explicava que a professora provida no lugar desde 1852 não vinha exercendo o seu ofício porque naquela cidade quase nenhuma menina se mandava à mestra (MADEIRA, 2007, p. 340-341). Para a instrução de todas as crianças, Rebelo da Silva mandava abrir o número de escolas primárias necessárias "ao ensino da leitura, escrita e cálculo, exercícios de gramática e princípios de geografia e de história de Portugal” (MADEIRA, 2007, p. 341). Em Moçambique funcionaria, ainda, uma "Escola Principal" de instrução primária cujo programa contemplava gramática portuguesa, desenho linear, geometria prática, escrituração mercantil, produtos naturais da colônia, e noções de física aplicada à indústria e à economia doméstica. Rebelo da Silva baseavase no espírito e na letra da reforma do ensino de Costa Cabral, de 1844, que considerava insuficiente a instrução primária tradicional, reduzida ao conhecimento da leitura, da escrita e das quatro operações aritméticas. Possivelmente para Rebelo da Silva interessasse mais uma instrução primária cujas competências necessárias incidissem mais sobre o saberfazer, como se de ensino técnico-profissional se tratasse:

Decidiu, então, dividir a instrução pública em dois graus e ampliar, com um carácter prático, os programas da instrução primária, introduzindo-lhe uma inovação que a tornava adaptável a contextos diferentes. Em parágrafo único, a reforma de Rebelo da Silva estipulava que "tanto o primeiro grau como o segundo

5 A segregação dos alunos em função do sexo foi eliminada com a independência de Moçambique, em 1975. Assim, as iniciativas de criação de um sistema escolar misto só se cristalizam no período pós-colonial, ainda que tenha havido sucessivas reformas legais de instrução primária que se seguiram ao Ato Colonial de 1930. 
poderiam compreender outros objetos de instrução nos lugares e à proporção" que o governo achasse conveniente. (MADEIRA, 2007, p. 338).

Na verdade, parece-nos ter-se tratado de uma tentativa de dotar as colônias de um ensino essencialmente prático, orientado para a rentabilização dos recursos disponíveis nas então províncias ultramarinas, iniciativa que coincidiu com um novo impulso de expansão e consolidação da soberania portuguesa em África, no início da segunda metade do século XIX, precisamente durante a década de 1850.

Segundo Sheldon, as autoridades estavam cientes do desejo das meninas em estudar, mas os professores disponíveis nesse momento para o sexo feminino eram considerados de precária qualidade comparativamente com os do sexo masculino, tendo sido praticamente impossível garantir que houvesse professoras antes de 1885. Com efeito,

Em Lourenço Marques, em 1855, uma escola de meninas tinha 25 alunas mas foi encerrada por seis meses devido à falta de professoras. As meninas usavam espaços públicos que quando fossem necessários elas deveriam abandoná-los. Somente em 1893 foi estabelecida uma base financeira para que as Irmãs Católicas construíssem uma escola cuja abertura contou com uma cerimônia pública, em que esse feito foi considerado um grande progresso (SHELDON, 1998, p. 597).

Segundo Sheldon, as meninas deviam ser preparadas para que seus filhos fossem os tão desejáveis cidadãos portugueses, fato que, a seu ver, revelava um conflito entre as ideias africanas e europeias sobre o papel social da mulher, vista como quem deveria corresponder às expectativas da sociedade como esposa e mãe. Outrossim, havia uma ênfase paralela no matrimônio e maternidade em todas as raças. Nesses esforços havia, também, as Missões protestantes Wesleyanas e Presbiterianas que construíam capelas, escolas e acampamentos ao longo do distrito de Lourenço Marques (atualmente Maputo). Os missionários suíços da Igreja 


\section{Revista de História e}

Historiografia da Educação

Presbiteriana conseguiram abrir suas escolas em 1891, apesar de dificuldades impostas por Portugal.

$\mathrm{Na}$ ótica do governo colonial português, na região norte de Moçambique, o grande obstáculo na escolarização das meninas era o fato de serem retiradas da escola pelos progenitores assim que atingissem a puberdade, e encaminhadas aos ritos de iniciação, algo que era comparado, pelo colonizador, a uma "prisão domiciliária de seis meses a um ano ou mais" (SHELDON, 1998, p. 598).

Este excerto revela uma importante particularidade da escolaridade obrigatória, cuja principal condição de implementação consiste no estabelecimento de bases legais para a penalização dos pais que não mandam seus filhos à escola, como também fica sujeita ao cumprimento dos deveres do Estado na oferta do ensino. Significa que, naquele momento, se o regime colonial português estivesse interessado em escolarizar cada vez mais negras e negros teria estabelecido um regulamento que complementasse o decreto de 30 de novembro de 1869, do Ministro de Estado da Marinha e do Ultramar (Luís Rebelo da Silva), que pela primeira vez instituiu o Ensino Primário obrigatório em Moçambique.

Em 1909 uma escola em Inhambane - região sul de Moçambique contava com 78 alunos, dos quais 15 eram meninas. Em Boroma, Tete região centro de Moçambique - havia em 1908, em uma escola Jesuíta, 180 meninos e 250 meninas, uma das raras vezes em que o número de meninas ultrapassou o de meninos (SHELDON, 1998). A ideia da escola mista ainda não se havia cristalizado até à entrada da segunda metade do século XX.

A tabela 2 mostra quão grandes eram as disparidades de gênero na instrução primária. De acordo com estes dados, a percentagem de meninas em escolas católicas, no período de 1909 a 1920, correspondia à nona parte do efetivo escolar total, ou seja, o número de meninos era cerca de nove vezes maior que o das meninas. Estes dados comprovam as bases históricas da situação de desvantagem numérica escolar das meninas face aos meninos. 


\section{Revista de História e \\ Historiografia da Educação}

Tabela 2 - Alunos matriculados em escolas católicas (1909-1920).

Fonte: SHELDON (1998, p.601).

\begin{tabular}{|cccccc|} 
Ano & Meninos & Meninas & Total & \% de Meninas & Escolas \\
\hline 1909 & $\mathbf{5 , 3 1 4}$ & $\mathbf{9 5 8}$ & $\mathbf{6 , 2 7 2}$ & $15.3 \%$ & 67 \\
1910 & & 887 & & & 54 \\
1911 & & 417 & & & 48 \\
1920 & 5,995 & 632 & 6,627 & $9.5 \%$ & 90 \\
\hline
\end{tabular}

Tabela 3 - Número de alunos por distrito e sexo (1940), em áreas rurais. Fonte: Dados do Censo da População em 1940 (população indígena de Lourenço Marques, 1940).

\begin{tabular}{|lcccc|}
\multicolumn{1}{c}{ Distrito } & Meninos & Meninas & Total & \% de Meninas \\
\hline Sul do Save (Sul) & 3,808 & 1,842 & 5,650 & $32.6 \%$ \\
Manica e Sofala (Centro) & 3,365 & 306 & 3,671 & $8.3 \%$ \\
Zambézia (Centro) & 846 & 72 & 918 & $7.8 \%$ \\
Niassa (Norte) & 855 & 566 & 1,421 & $39.8 \%$ \\
\hline \multicolumn{1}{c}{ Total } & $\mathbf{8 , 8 7 4}$ & $\mathbf{2 , 7 8 6}$ & $\mathbf{1 1 , 6 6 0}$ & $\mathbf{2 3 . 9 \%}$ \\
\hline \multicolumn{1}{c}{} \\
\hline
\end{tabular}

Duas décadas depois, e de acordo com a tabela 3, o número de meninas em escolas do Sul do Save - nas atuais províncias de Inhambane, Gaza e Maputo - e da região do Niassa - ao norte de Moçambique correspondia à terça parte do efetivo escolar. Por conseguinte, o número de meninos era cerca de duas vezes maior que o das meninas; o que em termos práticos significava um incremento da proporção de meninas que frequentavam as escolas, contrariamente ao cenário que se verificava em finais do século XIX. Terá contribuído para esta tendência o crescimento dos efetivos escolares das Missões Protestantes e as primeiras iniciativas da co-educação de meninos e meninas depois de 1935. Com efeito, enquanto em Niassa e no sul do Save as meninas representavam cerca de um terço do 
efetivo escolar global, no Centro, as meninas representavam cerca de $8 \%$ do efetivo escolar, ou seja, o número de meninos era cerca de 12 vezes maior que o das meninas. Os dados das tabelas 4 e 5 revelam que as escolas católicas acolhiam menos meninas do que meninos.

Tabela 4 - Matrículas em Escolas da arquidiocese de Lourenço Marques (1941-1954). Fonte: SHELDON (1998).

\begin{tabular}{cccccc} 
Anos & Escolas & Meninos & Meninas & $\begin{array}{c}\text { Total } \\
\text { (Meninos+Meninas) }\end{array}$ & \% de Meninas \\
\hline 1941 & 205 & 31,690 & 16,469 & 48,159 & $34.2 \%$ \\
1945 & 358 & 44,493 & 34,035 & 78,528 & $43.3 \%$ \\
1950 & 457 & 45,663 & 38,009 & 83,672 & $45 \cdot 4 \%$ \\
1954 & 542 & 52,914 & 43,958 & 96,872 & $45 \cdot 4 \%$ \\
\hline
\end{tabular}

Os dados da tabela 4, sobre as matrículas em escolas católicas circunscritas à Arquidiocese de Lourenço Marques, corroboram a tabela 2, ao apresentarem percentagem de alunas na ordem dos 34 a 45\% no período entre 1941 a 1954.

Tabela 5 - Meninas matriculadas em "Escolas para negros" das Missões católicas (1960). Fonte: SILVA (1960, p.68).

\begin{tabular}{lccc}
\multicolumn{1}{c}{ Dioceses } & $\begin{array}{c}\text { Meninas } \\
\text { matriculadas }\end{array}$ & Total de matrículas & \% de meninas \\
\hline Lourenço Marques & 52,140 & 111,699 & $46.7 \%$ \\
Beira & 11,567 & 39,962 & $28.9 \%$ \\
Quelimane & 16,913 & 57,504 & $29.4 \%$ \\
Nampula & 29,588 & 96,349 & $30.7 \%$ \\
Porto Amélia & 10,727 & 29,714 & $36.1 \%$ \\
\hline
\end{tabular}


Um cenário diferente, porém, é observável na tabela 5 que apresenta números de matrículas das meninas na ordem dos 30 a 46\%, por volta de 1960. O início dos anos 1960 é marcado por reformas no EP, motivadas pelo avanço dos movimentos nacionalistas que tinham como objetivo a libertar Moçambique e outras colônias africanas.

As escolas das missões para meninas, ao nível do ensino para negros, ministravam aulas de português, história, ciência, matemática, canto coral e desenho ${ }^{6}$. A legislação apresentava, igualmente, um currículo para meninas, cujo objetivo era a preparação da mulher nativa para uma vida "civilizada" Nestes termos, o currículo era dominado por conteúdos ligados à economia doméstica, segundo o estilo de vida europeu; por consequência, a minoria das meninas moçambicanas que frequentavam a escola tinham as suas aulas centradas na esfera doméstica. Cursos sobre a costura, culinária e cuidados a bebês e crianças constituíam uma forte mensagem sobre as responsabilidades da mulher em casa ${ }^{8}$.

\section{Gênero e educação}

\section{tradicional em Moçambique}

Durante o período colonial privilegiou-se os interesses de Portugal e promoveu-se um ensino desigual e excludente para os negros. Nesta fase, as questões de gênero associadas à educação implicavam também mais fatores de exclusão para as mulheres indígenas, que viam os seus direitos de cidadania restritos e o seu direito à educação limitado e desvalorizado, o que refletia o retrocesso a que o Estado ditatorial português empurrou a igualdade de gênero e das liberdades em geral, tanto em Portugal como nas colônias. Por consequência, numa forte revitalização do patriarcado político

6 Portaria n. 1.115 de 1930: Programa e ensino para as escolas primárias rudimentares.

7 Portaria n. 1.117 de 1930: Regulamento das escolas profissionais para indígenas do sexo feminino.

8 Idem. 


\section{Revista de História e}

Historiografia da Educação

e familiar, o Estado distanciou-se cada vez mais dos progressos que outros países tinham alcançado nestas áreas.

Na verdade, a cultura tradicional está assente em estereótipos igualmente fortes e de dominação masculina (a educação tradicional também separa meninos e meninas, o principal papel social da mulher é o de mãe e o casamento é uma instituição social incontornável), mas a introdução de modelos ocidentais promove a inferioridade das populações locais e da sua cultura e organização social, o que acentua ainda mais as desigualdades de gênero. Ou seja, as mulheres são inferiores por serem "indígenas", tal como o são os homens, face à população branca, mas são duplamente inferiores por serem mulheres, mesmo diante das mulheres brancas, que por serem de outra cor correspondiam aos modelos de mulher promovidos e socialmente aceitos, pelo Estado e pela Igreja Católica. No ambiente escolar, espaço concreto das políticas públicas educativas, a discriminação contra meninas pode elevar explicitamente através dos comportamentos dos professores e alunos, e através de certos aspectos de gestão da sala de aulas. Pode também funcionar de forma subtil através de estereótipos nos materiais de ensino e aprendizagem (LOCKHEED, 2010, p. 17).

O trabalho de Henri Junod, em 1895, quando dirigia a Missão Suíça em Lourenço Marques, "Usos e costumes dos bantu9", é importante para este trabalho. Ao centrar-se na tribo Tsonga ${ }^{10}$ transmite um olhar sobre o papel social da mulher, permitindo compreender alguns dos dados recolhidos sobre a sociedade local à luz da sua história e tradições seculares. O fato da mulher casada ou grávida ser enviada para casa da família do companheiro, passando a integrá-la e a cumprir aí vários deveres

9 A palavra "bantu" - significa humanos, sendo formada por "ba" ou "va" - prefixo que designa o plural - e "ntu" ou "inthu". Os bantu são um grupo etnolinguístico localizado principalmente na África subsaariana, que engloba cerca de 400 subgrupos étnicos. Estes povos eram agricultores, caçadores e ferreiros. Disponível em: <http://www.mz. one.un.org/por/Mocambique/Historia-de-Mocambique. Acesso em: 20 jun. 2015.

${ }^{10}$ A tribo Tsonga se estendia pelos territórios da antiga região do Transvaal (atualmente Mpumalanga) e Kwazulu-Natal - na África do Sul, Rodésia do Sul (atual Zimbábue) e Moçambique. 
cotidianos, assim como a tradição de pagamento da noiva através do lobolo ${ }^{11}$, têm raízes ancestrais:

A criança tsonga é sempre recebida com alegria por toda a família. Se é menina significa acréscimo de bois, que permitirão mais tarde comprar mulher para um dos filhos; é pois, não só um aumento de riqueza, mas também aumento do número dos membros da família. Se é menino, não há enriquecimento material direto, mas o clã torna-se mais forte e o nome do pai é glorificado e perpetuado (JUNOD, 1974, p. 53).

É clara a similaridade verificada atualmente nas comunidades, onde se nota uma influência da Igreja. Esta mescla entre tradição e religião é vista como intensificando a desigualdade social verificada entre homens e mulheres, incluindo no acesso à escola, colocando estas últimas em inferioridade, sobretudo no meio rural onde há maior domínio social da cultura tradicional. O trabalho de Junod (1974) mostra como alguns valores e tradições ancestrais ainda estão enraizados nas comunidades bantu. Apesar de transformações ocorridas nas últimas décadas devido à guerra, que destruiu infraestruturas do país e parte significativa do seu tecido e instituições sociais, como os casos das redes de solidariedade que caracterizavam a família alargada e as alianças de parentesco típicas da vida cotidiana das populações, ainda que haja convivência com elementos da modernidade introduzidos por influência de organizações supranacionais.

11 O lobolo é um costume cultivado, até hoje, em vários países africanos incluindo
Moçambique. Segundo esta tradição, a família da noiva recebe dinheiro ou outras
riquezas, ou dote, pela "perda" que representa o seu casamento e a consequente ida para
outra casa. Para muitas mulheres moçambicanas, a cerimônia do lobolo é mais
importante que o casamento. A tradição do lobolo tem sido tema de muitas controvérsias
em Moçambique e não só. Mesmo depois da independência, que tentou desvalorizar
alguns dos antigos costumes, o lobolo permaneceu e muitos jovens ainda valorizam-no.
Por exemplo, o ex-presidente da África do Sul, Nelson Mandela, deu 55 cabeças de gado
como lobolo para a família de Graça Machel, esposa do falecido presidente de
Moçambique Samora Machel. [Texto adaptado] Disponível em: <http://www.dw.com/p
t/lobolo-os-casamentos-em-mo\%C3\%A7ambique-ontem-e-hoje/a-3657678>. Acesso em
18 ago. 2016. 


\section{Revista de História e}

Historiografia da Educação

Um dos problemas que caracterizam a desigualdade entre homens e mulheres prende-se ao acesso à escola e a escolarização completa. No meio rural, a educação formal é muitas vezes alheia ao processo de construção da identidade de indivíduos, sendo considerada desnecessária para o desempenho do seu papel social, sobretudo no caso dos indivíduos do sexo feminino. O papel social da escola é diferente para vários grupos da população, sobretudo tendo em conta a distinção entre o meio rural e urbano, o que obriga a uma "negociação cultural” para a sua promoção.

\section{Considerações finais}

O presente trabalho teve por objetivo identificar e tipificar os possíveis fatores associados ao fenômeno do fraco acesso das meninas à escola primária moçambicana, desde a segunda metade do século XIX. Assim, fatores socioculturais ligados à hierarquização dos papéis sociais atribuídos aos membros da família, sobretudo à base do sexo, são a principal razão do fraco acesso das meninas à escola primária. No período colonial, a fraca escolarização das meninas ficou a dever-se ao fortalecimento de um modo de vida patriarcal em que as mulheres negras eram duplamente colocadas em segundo plano, por serem mulheres e ao mesmo tempo negras, tanto pelas políticas do Estado colonial, assim como pelo sistema religioso, que não só segregava o ensino por sexo, diferenciando as matérias para meninos e meninas, como também privilegiava a mão-de-obra masculina para o fortalecimento da sua economia capitalista. No que se refere, especificamente, aos usos e costumes locais, o trabalho de Junod mostra como a sociedade tradicional, ainda hoje predominante em Moçambique, privilegia os meninos em detrimento das meninas. Devido à manutenção desse modelo de educação da sociedade moçambicana, este fenômeno prevalece até aos dias atuais, fato que por sua vez influencia o acesso da mulher a determinadas 
atividades, o que em último caso cria desigualdades de oportunidades, rendimentos e possibilidades de exercício de poder, devido à fraca capacidade de participação ativa da mulher em diversas áreas que exigem um certo nível de instrução.

No período pós-independência, impulsionado pelo projeto de construção de uma república socialista em Moçambique, apesar da aprovação legal do princípio de obrigatoriedade da escolarização de meninos e meninas, pela Lei n. ${ }^{0}$ 4/83, de 23 de março (Lei do Sistema Nacional de Educação), este princípio não foi posto em prática porque $o$ governo não regulamentou a lei do sistema de ensino. Assim, tanto o governo quanto as famílias, não tiveram um instrumento legal que os obrigasse a escolarizar as crianças, acabando, as meninas, por ser as mais prejudicadas devido à ação nefasta dos fatores aqui referidos.

$$
* \quad * \quad *
$$

\section{Referências}

ANDRADE, X.; LOFORTE, A. M.; OSÓRIO, C.; RIBEIRO, L.; TEMBA, Eulália. Famílias em Contexto de Mudanças em Moçambique. Maputo: WLSA Moçambique, 1998.

COLÔNIA DE MOÇAMBIQUE. Dados do Censo da População em 1940: população indígena de Lourenço Marques, 1940.

DELORS, J. Educação, um tesouro a descobrir. Porto: Edições ASA, 1996. JUNOD, H. A. Usos e costumes dos Bantu. 2. ed. (Tomo I). Lourenço Marques: Imprensa Nacional de Moçambique, 1974.

LOCKHEED, M. Gender and social exclusion. Jointly published by The International Institute for Educational Planning: Paris/France \& The International Academy of Education: Brussels/Belgium, 2010. 
MACHEL, S. M. Educar o Homem para vencer a guerra, criar uma sociedade nova e desenvolver a pátria (Coleção estudos e orientações, $\mathrm{n}$. 2). Maputo: Departamento do Trabalho Ideológico da FRELIMO, 1978.

MADEIRA, A. I. Ler, escrever e orar: uma análise histórica e comparada dos discursos sobre a educação, o ensino e a escola em Moçambique, 18501950. Tese (Doutorado) - Universidade de Lisboa, Lisboa, 2007.

MINED. Plano Curricular do Ensino Básico: objetivos, política, estrutura, plano de estudos e estratégias de implementação. Maputo: MINED, 2003.

NAFUKO, F.; AMUTABI, M.; OTUNGA, R. Foundations of adult education in Africa. Cape Town: UNESCO, 2005.

SHELDON, K. I studied with Nuns, learning to make Blouses: gender ideology and Colonial Education in Mozambique. The International Journal of African Studies. v. 31, n. 3, p. 595-625, 1998.

SILVA, M. C. T. L. As Missões Católicas femininas. Lisboa: Junta de Investigações do Ultramar, 1960.

UNESCO. Educação para Todos: o compromisso de Dacar. Brasília: UNESCO, 2001.

VAN KLAVEREN, M.; TIJDENS, K.; HUGHIES-WILLIAMS, M.; MARTIN, N. R. An overview of Women's work and employment in Mozambique: Decisions for Life Millennium Development Goal 3 Project, Country Report $\mathrm{n}^{\mathrm{o}}$ 1. Netherlands: University of Amsterdam/Amsterdam Institute for Advanced Labour Studies, 2009.

Recebido em 04 de fevereiro de 2017. Aprovado em 12 de março de 2017. 